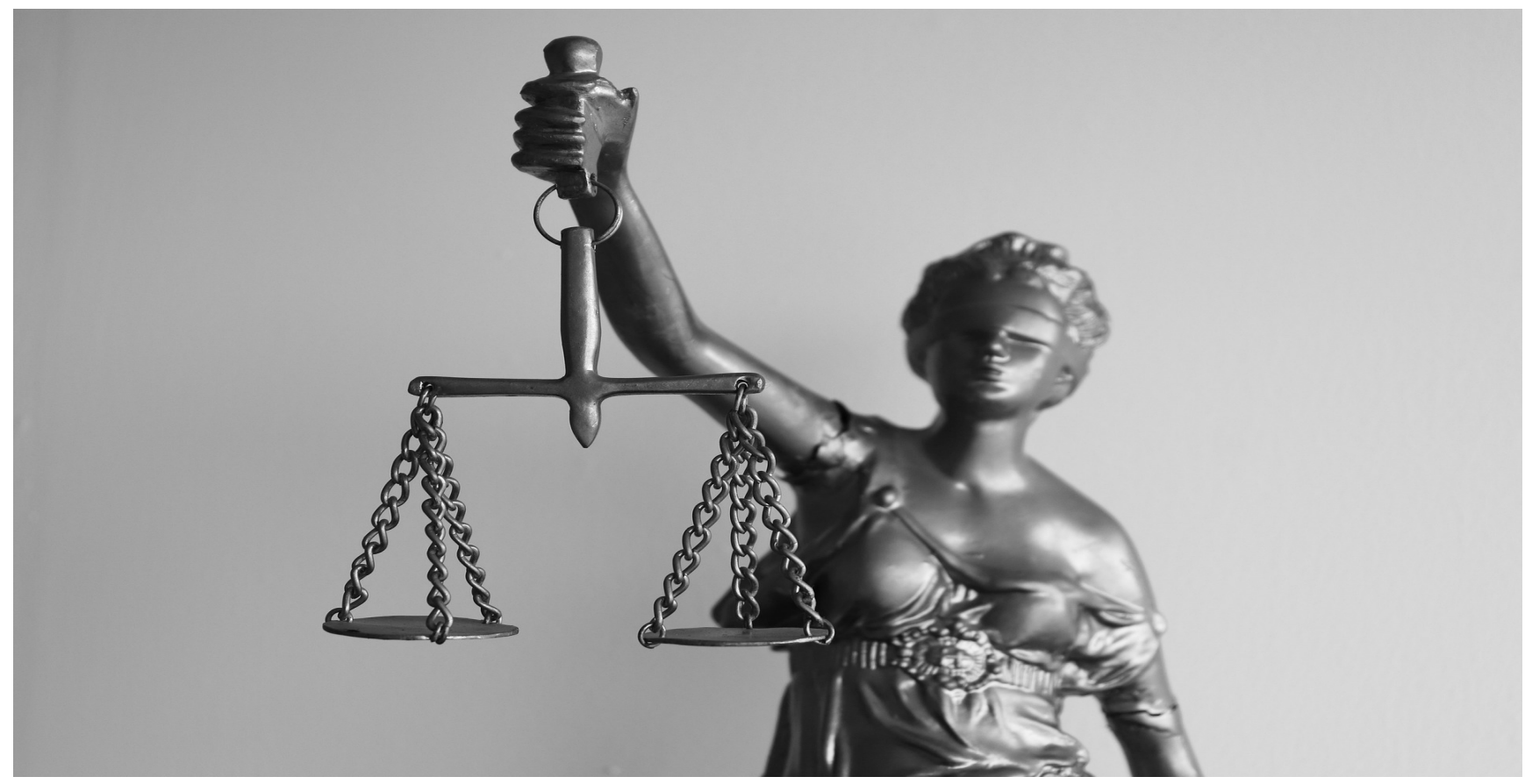

\title{
Positivismo y Positivismo Jurídico
}

\section{Positivism and Legal Positivism}

\section{David Mercado-Pérez}

Especialista en Derecho Público, davidmercadoperez@yahoo.com, https://orcid.org/orcid/0000-0002-5646-0052,

Universidad de Cartagena, Cartagena de Indias, Colombia 


\section{Resumen}

El Positivismo nace en la segunda mitad del siglo XIX, pero sus raíces son más profundas como para considerar que COMTE es su aislado creador. En realidad, el postulado consistente en considerar solo como ciencias a las naturales o a las que pueden usar sus métodos, es anterior a la doctrina comtiana. Se estima que nació en el entorno cultural que dio origen esa gran escuela de la burguesía industrial francesa "La Ecole Polytechnique" de París. Dicha escuela generaría una atmósfera de "secularización" y "optimismo" científico basados en el agnosticismo y el libre pensamiento ("no necesité de Dios para que mis ecuaciones cuadrasen" Laplace"). La Ecole se creó en 1794, durante la revolución, por el general y físico LAZARE N. CARNOT y el gran matemático GASPARD MONGE con el fin de capacitar a quienes habrían de dirigir el estado nacido de la revolución. La palabra "POSITIVISMO" como tal, la usa por vez primera SAINT SIMON, en la expresión "FILOSOFÍA POSITIVA" con la cual se refería al periodo que seguía a la post - revolución de 1789 obligada a tener su propia "FILOSOFÍA" de la razón. El positivismo necesitó de una lógica para soportar racionalmente sus enunciados y COMTE y sus seguidores la encontraron en ese monumento del pensamiento humano que es el "SYSTEM OF LOGIC" de JOHN STUART MILL. Con MILL, sucede algo clave, los hechos experimentales tan caros a los positivistas pierden prácticamente su corporeidad inicial cuando la mente humana elabora conceptos para convertirse a la vez en empirismo humano mental, es decir, en estados de la conciencia o percepciones de la conciencia (lo subjetivo volcándose al mundo); por esto, los "juicios universales" de la lógica griega tradicional fueron declarados sin valor y sólo son válidos los que inductivamente se construyen a partir de observaciones particulares.

Palabras clave: Ciencia, Conocimiento, Derecho, lusnaturalismo, Positivismo, Sociología.

\section{Abstract}

Positivism was born in the second half of the 19th century, but its roots go deeper than considering COMTE as its isolated creator. In reality, the postulate consisting in considering only natural sciences or those that can use their methods, predates Comtian doctrine. It is estimated that he was born in the cultural environment that gave rise to that great school of the French industrial bourgeoisie "La Ecole Polytechnique" in Paris. Such a school would generate an atmosphere of scientific "secularization" and "optimism" based on agnosticism and free thought ("I didn't need God to make my equations fit" Laplace "). The Ecole was created in 1794, during the revolution, by the general and physicist LAZARE N. CARNOT and the great mathematician GASPARD MONGE in order to train those who were to lead the state born of the revolution. The word "POSITIVISM" as such is used for the first time by SAINT SIMON, in the expression "POSITIVE PHILOSOPHY" with which he referred to the period following the post-revolution of 1789 forced to have his own "PHILOSOPHY" of reason. Positivism needed a logic to rationally support its statements and COMTE and its followers found it in that monument of human thought that is the "SYSTEM OF LOGIC" by JOHN STUART MILL. With MILL, something key happens, the experimental facts so expensive to the positivists practically lose their initial corporeality when the human mind elaborates concepts to become simultaneously mental human empiricism, that is, states of consciousness or perceptions of consciousness ( the subjective turning to the world); therefore, the "universal judgments" of traditional Greek logic were declared worthless and only those that are inductively constructed from particular observations are valid.

Keywords: Science, Knowledge, Law, Natural Law, Positivism, Sociology. 
Introduccion

El Positivismo sostiene que en lo cognoscible por el ser humano es la experiencia que nace de modo inmediato de la realidad, por lo que se sustenta en la concepción cartesiana de la separación del sujeto que conoce de la realidad cognoscible; así, la ciencia se despoja de adherencias especulativas para conocer mejor la realidad y preveer su evolución futura.

Nace formalmente en la segunda mitad del siglo XIX, pero sus raíces son más profundas como para considerar que COMTE es su aislado creador, por sí mismo. En realidad, el postulado consistente en considerar solo como ciencias a las naturales o a las que pueden usar sus métodos, es anterior a la doctrina comtiana. Se estima por los historiadores de la ciencia que nació en el entorno cultural a quien dio origen esa gran escuela de la burguesía industrial francesa "La Ecole Polytechinque" de París, dicha escuela a su vez generaría una atmósfera de "secularización" y "optimismo" científico basados en el agnosticismo y el libre pensamiento ("no necesité de Dios para que mis ecuaciones cuadren" Laplace"); La Ecole se creó en 1794, durante la revolución, por el general y físico LAZARE N. CARNOT y el gran matemático GASPARD MONGE con el fin de capacitar a quienes habrían de dirigir el estado nacido de la revolución. La palabra "POSITIVISMO" como tal, la usa por vez primera SAINT SIMON, en la expresión "FILOSOFÍA POSITIVA" con la cual se refería al periodo que seguía a la post - revolución de 1789 obligado a tener su propia "FILOSOFÍA" de la razón. Es de anotar que SAINT SIMON fue maestro de COMTE y este fue uno de los discípulos de La Ecole, en donde después sería profesor [1].

El positivismo se expandió por Europa en la medida en que se industrializaba y el liberalismo se extendía y se erigió en la "forma mentis" o paradigma de los científicos, para luego serlo de los filósofos, los literatos y los historiadores. Si bien COMTE es el creador formal de la palabra "POSITIVO y POSITIVISMO", antes de él ya existía una gran tradición al respecto. EL POSITIVISMO [2] debe verse como un amplio movimiento filosófico - cultural que generó en su interior varios matices en Alemania, Inglaterra y sobre todo, en Francia. Aparte del "culto" a las "ciencias naturales" ya dicho, junto con el desprecio a la teología y la metafísica se puede señalar como otra característica esencial la de tener a las ciencias como único instrumento válido para obtener el "progreso humano" en lo científico, y en lo social, como ciencia aplicada al bienestar general.

\section{El Positivismo Filosófico.}

La palabra "positivismo" sirve para designar la doctrina y las escuelas que tienen su origen en las teorías de AUGUSTE COMTE, su nota básica es la de solo aceptar lo existente en la realidad, o sea, los llamados "HECHOS POSITIVOS" y las relaciones entre ellos. Se fundamenta en la cualidad de exactitud de las llamadas "CIENCIAS NATURALES", rechaza por definición las cuestiones metafísicas y teológicas por la imposibilidad de comprobarlas experimentalmente. En consecuencia acepta la experimentación como método científico y los hechos priman sobre las ideas [3].

El positivismo necesitó de una lógica para soportar racionalmente sus enunciados y COMTE y sus seguidores la encontraron en ese monumento del pensamiento humano que es el "SYSTEM OF LOGIC" de JOHN STUART MILL. Con MILL, sucede algo clave, los hechos experimentales tan caros a los positivistas pierden prácticamente su corporeidad inicial cuando la mente humana elabora conceptos para convertirse a la vez 


\section{0}

en empirismo humano mental, es decir, en estados de la conciencia o percepciones de la conciencia (lo subjetivo volcándose al mundo); por esto, los "juicios universales" de la lógica griega tradicional fueron declarados sin valor y sólo son válidos los que inductivamente se construyen a partir de observaciones particulares.

Ahora bien, esta "universalidad" así construida no tiene el carácter absoluto de la lógica griega, sino que es una universalidad circunscrita a las particularidades demostradas empíricamente, por lo que en la práctica es una "particularidad más" donde los conceptos que la contienen poseen más comprensión y menos extensión. Lo que hacemos es pasar de lo particular específico (mucha comprensión, poca extensión) a una particularidad más amplia, pero nunca con la pretensión de un enunciado general, tal cual son los "juicios universales" [4].

Lo anterior nos lleva a otro aspecto claro del positivismo, la "EVOLUCIÓN", que desde DARWIN y HAECKEL, fue desde su desde su principio mismo más una "filosofía positiva", como se acaba de explicar que una "ley empíricamente inducida". Tal como fue anunciada la "evolución" tenía varios puntos oscuros por no poderse probar experimentalmente, sobre todo el célebre "eslabón perdido" que según DARWIN probaría la transformación paulatina del mono en hombre, empero se aceptó positivamente la "Teoría" Darwinista, sobre el supuesto de que las pruebas irían apareciendo, porque al extrapolar otras "leyes científicas" filosóficamente podríamos tener la convicción de que la evolución era fenomenológicamente cierta, aunque no se supiese bien como había sido.

Así mismo [5] con la "teoría de la evolución" se proclama implícitamente una "fe en la ciencia", fe que en sí no es empíricamente comprobable, por lo que la ciencia se convierte, ella misma en sí, en una forma de religión. Esta es una contradicción del discurso positivista, contradicción que dará origen al materialismo del siglo XIX, base del marxismo, con el fin de superarla y a la vez eliminar la religión tal como SPENCER lo había considerado.

COMTE, motu proprio, creará una nueva "ciencia", la Sociología, encargada de estudiar la etapa actual del hombre, que llama "Edad Positiva", donde prima la razón, y supera las etapas anteriores: la metafísica y la religión. Esto es algo llamativo, porque COMTE no estableció un método para abordar empíricamente los fenómenos que integran su objeto de estudio y además no precisó tales fenómenos cartesianamente, por lo que aparecía así una problemática parecida a la "teoría de la evolución", una fe en la ciencia no comprobable ella en si, por lo que la sociología era al parecer una suerte de sentimiento religioso spenceriano.

Al final de la obra, COMTE asume una dirección ostensiblemente mística, en la cual el "sentimiento" tiene la primacía sobre el "conocimiento" y el logos; por consiguiente, el ARTE lo considera como superior a cualquier otra actividad humana y que la HUMANIDAD COMO TODO es gran ser del cual cada individuo es parte, este mega-ser es "inmortal" y en la edad positiva o de la razón, todas las ciencias y sus saberes deben encaminarse al perfeccionamiento de la humanidad como ese todo. Todo lo expuesto lo encamina a idear una "religión de la humanidad" que es una utopía nueva que será capaz de resolver todos los problemas sociales ya que estos socialmente predominan por ser los que impulsaban el saber, o ser la "civilización" y permiten una mejor convivencia, la política y donde sus sacerdotes serán los científicos. 
Autores como [6] señalan que el "progreso" es así una religión, o mejor, la historia es lineal y en vez de "salvador", tiene "salvación" en el hombre mismo. Empero, el positivismo por ser puramente burgués, era usado por el liberalismo como la parte racional o científica de su ideología para enfrentar a la iglesia, unida a las fuerzas conservadoras que defendían el latifundismo (BENITO JUÁREZ, en México, los radicales en Colombia, por ejemplo).

\section{Evolución Histórica}

Históricamente, como precedentes del positivismo, casi todos los tratadistas hablan de EPICURO y su doctrina, delempirismo inglés del siglo XVII (BACON) y del enciclopedismo francés(VOLTAIRE,D’ALEMBERT), sinembargo, en el recorrido evolutivo del Positivismo se encuentran tres formas:

- El Positivismo Empírico o Gnoseológico. Establecido por COMTE y sus seguidores, donde la filosofía es ciencia en las condiciones analizadas porque se usa el método de las ciencias naturales y al analizar la evolución de las ciencias, es al mismo tiempo una filosofía de la historia.

- El Positivismo Metodológico. Desarrollado por el sensorialismo del físico ERNST MACH que une la concepción de COMTE con la de HUME y postula que la única realidad posible es la que se nos ofrece como sensaciones. En ella existen variantes, tales como el empirocriticismo de AVENARIUS, el Positivismo Idealista de VALHINGER y algunas corrientes neokantianas. Existe otra variante, clásica y más sólida, la de EMIL DURKHEIM.

- El Positivismo Lógico. Llamado también neo - positivismo, nacido en Inglaterra a partir del trabajo lógico de STUART MILL y planteado por SPENCER, se proyecta hoy con la lógica simbólica de RUSSELL [7].
El Positivismo se nos presenta así, como una filosofía que no busca causas (ya que entonces debería enfrentar el problema de la "causa incausada") sino leyes, cuestión que debe lograrse con los criterios de precisión y certeza aplicados a los resultados. El mismo y sus resultados son "históricos" en cuanto que, cuando la sociología estudia el pasado de sus estadios teológico y metafísico se logra la explicación racional del presente, como "este presente", el cual es relativo y por ende inestable y sirve a la vez de base del progreso, razón de ser de la filosofía positiva que influye plenamente en la misma condición humana, en su naturaleza y como una expectativa racional y razonable de un futuro cada vez mejor y más promisorio (optimismo histórico filosófico) [8].

- El Positivismo de Kelsen. Con base en lo estudiado en el ACÁPITE anterior, enfrentamos en este un interrogante fundamental: ¿Es o no el positivismo de KELSEN heredero del pensamiento positivista de COMTE, o de algunas de las variantes del mismo que después surgieron?

Autores como [9] comienzan por decir que la noción de "positivismo" como "STAATSRECHTS" o "DERECHO DEL ESTADO" nace en la primera mitad del siglo XIX y se propone hacer del "DERECHO" una ciencia que participa de la "NATURALEZA" al igual que las ciencias naturales; para lograrlo, la "LEY" se convierte en el centro de toda atención. Este fenómeno es complejo y se adapta de múltiples modos a las tradiciones jurídicas anglosajonas, germánicas y francesas, por una parte. Por la otra, bajo el influjo del empirismo, están convencidos acerca de que el "método científico" lo es todo. En especial en Francia y en los estados alemanes de tradición capitalista - burguesa, que estiman como necesidad política que la "ley positiva" o "norma del Estado" debe ser el único objeto del Derecho como "ciencia positiva", para así dejar a un lado los "derechos" 


\section{2}

del "ANCIEN REGIME". Así, la ley seria la "única expresión" de la "voluntad general" de que habla ROUSSEAU y los contractualistas liberales.

Enverdad existeunamotivación más importante aún y que queda implícita en el discurso de estos primeros cultores del "DERECHO DEL ESTADO”,resultaqueDESCARTESestablecióla cientificidad de la modernidad sobre la base de la objetividad absoluta al constatarse que los "sentidos se equivocan en sus percepciones" por lo que los "métodos subjetivos" griegos fueron despreciados, la "verdad" estaba en el mundo o PHYSIS y allí se "hallaba" aplicando la "duda metódica". El Derecho solo podía ser tenido como "ciencia" si y solo si podía hallarse por fuera del sujeto, en la PHYSIS, procediendo cartesianamente.

\section{Hans Kelsen}

HANS KELSEN nació en la Praga en 1881, ciudad que junto con el antiguo reino de Bohemia - Moravia, hacía parte del imperio Austro-Húngaro, imperio al que el gran MUSIL, autor de "El Hombre sin Atributos", novela que disecciona al "burgués" de su época en el contexto austríaco en particular y alemán en general, como un mediocre que vive según la apariencia que proyecta y lo que proyecta es lo que el amaestramiento hace de él, ocupado solo en pavonearse con su riqueza, redenominó "KAKANIA", por que en cierto sentido dicho imperio era una ficción al ser un Estado artificial, pura creación del intelecto Habsburgués que ignoraba la dura realidad geopolítica de todos los nacionalismos de los pueblos que esa dinastía dominaba; es más, lo que hizo el "Milagro" de que durara fue el "Teatro de Kakania" y su consumado actor principal, el emperador Francisco José quien por casi 70 años desempeñó magistralmente su papel, tanto, que usaba los tics de los actores consumados, es donde nuestro jurista, judío de Praga, estudia Derecho, en la entonces emblemática universidad de VIENA, capital de esa Kakania, pasando luego a las de HEIDELBERG y BERLÍN. Entre 1911 a 1930, será profesor de Derecho Público y de Filosofía del Derecho de la Universidad de VIENA y en el transcurso de esos veinte años de docencia creará lo que se conoce hoy como "la Escuela Jurídica de Viena" de la cual será su gran maestro. Su "teoría" no es producto de un único y gran chispazo de su genio, la irá edificando paso a paso en sus obras: HAUPTPROBLEME der STAATSRECHTTSLEHRE (1911); ALLGEMEINE STAATS LEHRE (1925); y en su archiconocida REINE RECHTSLEHRE [10].

\section{Marco Histórico}

Hecha esta breve introducción es necesario establecer un marco histórico que permita delimitar la temática a tratar y el posterior debate, así como una mejor comprensión de lo que se pretende estudiar, es necesario entender la realidad histórica de Hans Kelsen, porque es muy fácil criticar una teoría desde el presente y más si se ignoran los momentos históricos que lo llevan a crear dicha teoría. Para empezar es necesario establecer ¿Qué se entendía por derecho constitucional entre 1880 y 1914 en Europa central? [11].

Lo primero que encontramos es que NO había derecho constitucional en Europa central, ¿Qué era Europa central en este periodo? Dos grandes imperios, el segundo Reich alemán creado por Bismarck y el imperio austro húngaro que venía desde la edad media y había evolucionado solo desde una perspectiva racional teniendo en cuenta que el derecho constitucional es una criatura liberal lo más ajeno a ese par de imperios era la noción de derecho constitucional, no se podía hablar de derecho constitucional porque austro Hungría técnicamente no tenía una constitución y Alemania tenía una constitución particular redactada por Bismarck en una noche, que en la mañana siguiente se la dictó 
a su secretario privado y, luego, dicho texto lo refrendaron los príncipes que se federaron con Prusia para darle corporeidad política a la unidad germánica; es una constitución que no encaja en el contexto del constitucionalismo liberal ya que técnicamente es autoritaria al no emanar de la voluntad del pueblo, carece de contrato social, así, la constitución de Bismarck expresamente parte de la premisa de que es una de aquellas que los historiadores llamaron constitución graciosa o constitución otorgada por el príncipe, un acto de benevolencia del príncipe para con sus súbditos [12].

Por ello, el parlamento del segundo Reich alemán solo podía legislar en ciertas y especificas materias, por otro lado, de su seno no se generaba gobierno alguno dado que este lo formaba el emperador o Káiser como a bien quisiese sin responsabilidad frente al parlamento. En el imperio austrohúngaro lo que había era un estatuto fundamental del imperio, tal como se va a dar desde la caída de napoleón y el congreso de Viena de 1815 hasta la llegada de Francisco José II al trono, donde se hace un pacto dinástico con los húngaros a partir de una sublevación de los húngaros contra los austriacos, estableciéndose por un pacto dinástico la llamada doble corona del Danubio, la austriaca y la húngara donde el emperador personifica la unidad, pero cada reino es autónomo para dirigir su propia política interior. Austria-Hungría se convirtió en un gigante con pies de barro que estaba destinado al colapso en una guerra, como en efecto acaecerá en la I guerra mundial. La monarquía Austro Húngara desaparece [13].

La segunda pregunta que nos tenemos que hacer es ¿que enseñaba Kelsen? Kelsen enseñaba lo que en Alemania se empezó a llamar en el último tercio del siglo XIX, Teoría General del Estado y NO Teoría Constitucional, que era considerada una mezcolanza de sociología con historia, desde la perspectiva del nacionalismo alemán, es decir desde la perspectiva de Savigny y la escuela histórica alemana, perfeccionada por Jellinek hacia 1890 cuando escribe su famoso tratado sobre la teoría general del estado, así pues hablar de teoría constitucional era hablar del estado y todo lo que eso implicaba y NO hablar del supuesto liberal de lo que es el estado o como debe entenderse este desde la perspectiva contractualista [14].

Para un alemán de 1890 carecía de sentido ponerse a hablar entonces de un derecho constitucional basado en la jurisprudencia de los jueces como límite del poder, por que implicaba aceptar que el emperador alemán tenía un poder limitado y desde el punto de vista de la doctrina del estado germánico $\left(2^{\circ}\right.$ $\mathrm{REICH}$ ) el emperador encarnaba el espíritu del pueblo, aquí tenemos el marco histórico del problema clave que va a enfrentar Kelsen, este es marco en el cual nos enfoquemos para resolver la pregunta acerca de ¿cómo hablar de derecho constitucional dentro de una cultura y dentro de unos estados que no habían tenido una evolución liberal, como crear de derecho constitucional de una manera técnica y definida sin tener que usar la terminología liberal, está es la matriz de los positivismos no liberales, porque Kelsen es consciente de que no puede basar eso en la evolución liberal británica o francesa que son cuerpos extraños en Alemania y en Austria ¿Kelsen es un positivista no liberal? No, él pensaba como liberal pero al no usar el vocabulario liberal dejó la semilla de los positivismos no liberales en sus propios escritos y manifestaciones teóricas porque si hablaba de liberalismo hablaba de algo irreal en el contexto en que el dictaba sus clase en Viena entre 1890 y 1915 , el otro aspecto a subrayar radica en que el constitucionalismo liberal anglosajón, francés y los que le siguen al basarse en la idea de la soberanía del pueblo, automáticamente rompían con el principio teocrático en que basada su legitimidad la corona austrohúngara. La dinastía de los 


\section{4}

Habsburgo siempre postuló desde la edad media que su corona la tenían por la gracia de dios, era así imposible de buenas a primeras que el imperio sin dejar de ser imperio se volviese monarquía parlamentaria, era pedir peras al olmo [15].

Por otra parte [16] en lo que al Derecho respecta, KELSEN realiza esta labor de modo magistral, él es un intelectual de razonamiento impecable pero ello no significa que solucione impecablemente todos los problemas cuya solución acomete. Sin embargo su "Teoría Pura" es el texto más apasionante y si se quiere, hermoso, realizado por un pensador del Derecho, donde se propone una construcción del IUS con pretensión científica. De allí que comience con la reflexión de que toda ciencia parte de identificar y unificar su objeto pero que el derecho al desarrollar "Técnicas" jurídicas en ves de unificar y delimitar su objeto, en realidad lo duplica y muchas veces esta duplicación es multiplicadora. Por lo tanto se impone una tarea, que el mismo llama "Superación de los dualismos jurídicos”. ¿Cuáles son estos?

El que existe entre Derecho Subjetivo y Objetivo, entre Derecho Nacional y Derecho Internacional, entre Derecho Natural y Derecho Positivo y el más importante, el de Derecho y Estado, entre otros. Pretende ir así del todo a la unidad para que epistemológicamente el derecho sea ciencia por medio de tener un único objeto de estudio. Por haberse atrevido a hacerlo, independiente de cualquier valoración que se haga de su Teoría Pura, KELSEN es parte de la historia del Derecho [17].

Resumamos su Reine Rechtstehre / General Theory. Si consideramos al Derecho como una realidad independiente, objetiva, ya que "El mundo de lo que se puede decir es el de la lógica y la ciencia y el mundo de lo que no se puede decir es el de lo místico", según el "Círculo de Viena", la ciencia jurídica debe ser una disciplina autónoma; si es ciencia, el Derecho debe tener desde el inicio un objeto definido, delimitado; esta definición nos impone depurar al Derecho, como objeto de la ciencia jurídica, de mezclas con otros conocimientos y otros objetos propios de otras ciencias [18]. Este principio metódico es la base de la teoría pura / teoría general y de todas las doctrinas de la "Escuela Jurídica de Viena". Las normas o leyes que integran el ordenamiento positivo existente en virtud de determinados procesos sociales que explican su origen (fuente material del derecho), responden a fines precisos, que surgen de los objetivos específicos que se desean conseguir cuando la comunidad política se organiza jurídicamente y las mismas están sometidas a "criterios superiores" de valoración porque el derecho positivo no es justo por el solo hecho de existir. Empero, afirma KELSEN, todas las anteriores consideraciones no interesan al jurista porque están por fuera de su objeto de conocimiento y para nada deben influir en la construcción de la cientificidad del Derecho. Este es el postulado básico sobre el que se erigen las doctrinas de la Escuela Jurídica Vienesa [19].

Metodológicamente, el operador jurídico usa la teoría del Derecho, y la construye, dicho sea también, de una manera similar a la geometría de EUCLIDES. Así como la geometría se concentra en el estudio de las formas y de sus estructuras, formas posibles que pueden adoptar los cuerpos como estos se conectan, haciendo de esto su objeto; dejando a un lado su origen, sus propiedades materiales, su uso - la construcción física de ellos, la forma y solo ella es el "fenómeno geométrico"; así es, exactamente, el modus operandi del jurista. El "fenómeno jurídico" es la forma de la norma y sus estructuras, este y solo este es el objeto de una investigación pura del Derecho [20].

Lo demás, el origen de las normas, las instituciones, el fin político, el fin social, su justificación, NO PERTENECEN A LA 
El Valor Justicia y el Positivismo Kelseniano

El problema de la justicia, es el que mayores controversias ha suscitado a través de la historia, KELSEN como gran jurista y teórico del derecho no fue ajeno a esta problemática y realiza un estudio exhaustivo sobre el tema para poder establecer porque el tema de la justicia no es un tema propio del derecho, y se esfuerza por demostrar y controvertir las diferentes reglas de justicia que se han intentado crear a través de la historia. A su vez este argumento puede ser utilizado para rebatir la idea de incluir derechos fundamentales al interior de una Constitución [21].

Se puede hablar de justicia en el derecho positivo desde una perspectiva Kelseniana?

Para Kelsen la respuesta es un no rotundo, tengamos en cuenta que para Kelsen la práctica jurídica debe abandonar por completo cualquier referencia a la justicia como suscitador de reflexiones y argumentos. Concebir algo jurídicamente significa exclusivamente concebir las normas que sirven como sustrato de sentido a los hechos naturales. Un hecho natural solo es jurídico ( o antijurídico) en virtud de una norma que recoge tal hecho y así aparece una frontera entre el derecho y las ciencias naturales : ambas parten de hechos naturales (los actos que conforman un delito pueden ser estudiados por físicos o químicos) pero ese conocimiento primario ( común al criminalista o al abogado) solo se torna jurídico una vez que el hecho ha sido puesto en relación con la norma que lo tipifica... la moral en el derecho equivale a la justicia, dice Kelsen. "justicia" significa un valor absoluto, un orden superior y diverso frente al derecho positivo más allá de toda experiencia, y capaz de sancionar a los diversos sistemas positivos con los calificativos de "justo" o "injusto". Pero en éste sentido, la justicia no es más que una quimera de los hombres, "como lo prueba las historia del espíritu humano, que se afana en vano por la solución de este problema".

La justicia entendida como un orden absoluto de valores y normas, es, en la perspectiva del conocimiento racional (esto es, orientado por la experiencia) un imposible epistemológico. "toda tentativa de esa índole-explica Kelsensolo ha conducido hasta ahora a fórmulas completamente vacías", y aquí podemos apreciar que han sido infinidades las fórmulas que se han desarrollado a través de la historia con la intención de racionalizar la justicia ejemplo claro de esto "dar a cada uno lo suyo" y viene inmediatamente la pregunta ¿qué es lo suyo?, lo "suyo" podría ser lo que el legislador diga que es, pero aquí se corre un riesgo enorme, porque, "¿Qué pasaría cuando el legislador definiera lo suyo como algo que sabemos atenta contra el ser humano?, lo "suyo" incluso podría en casos diferentes tener significaciones diferentes, si definimos justicia de esta forma, sería algo incompleto, más que incompleto, muy deficiente puesto que una fórmula de justicia inadecuada puede abrir de par en par la puerta a cualquier abuso. No olvidemos que sobre la entrada del campo de concentración de Buchenwald aparece la frase "a cada quien lo suyo"...cada orden social puede pensar de sí mismo que concede a cada uno lo "suyo" puesto que él mismo determina que es lo "suyo". Esto puede ser en verdad enteramente distinto en diferentes sociedades. Pero con ellos se evidencia que la doctrina de "a cada quien lo suyo" puede ser fácilmente mal usada, pues a cada orden político le es dable conceptuar que atribuye a cada quien lo suyo, inclusive cuando debe decidir que un grupo ha de recibir unos mínimos medios de subsistencia y otro una abundante [22].

Resultados

Así pues teniendo en cuenta esta evolución histórica constatamos que el concepto de 


\section{6}

derecho fundamental es incompatible con el positivismo jurídico, porque nació y se desarrolló desde y en el lus naturalismo, el derecho no ha podido y quizás nunca pueda desarrollar una teoría jurídica de los derechos fundamentales solamente podemos hablar de derechos fundamentales desde un contexto histórico-filosófico, pero el derecho no puede manejar el lenguaje de los derechos fundamentales en razón a que el lenguaje jurídico es incompatible con el filosófico del iusnaturalismo, el concepto de justicia griego tiene que ver con el cosmos y esta es otra concepción de la relación de Dios y del hombre. Esta concepción griega la destruye el cristianismo al separar a Dios y al hombre y hacer de la Iglesia la intermediaria, mientras que en la concepción griega, dios y hombre están en una constante interacción. Por esto el concepto de justicia depende de lo ético en la phronesis es algo que el hombre puede alcanzar, perfeccionándose éticamente [23].

"Phronesis significa prudencia y es una de las etapas o escalones para alcanzar la sophia, la filosofía para los griegos era la identidad plena del ser humano con la sabiduría del cosmos y hacía del que alcanzaba la filosofía un dios, con un rostro que le podía mostrar a los dioses, en la concepción griega los seres humanos nacíamos como dioses potenciales y a lo largo de la existencia teníamos el deber de convertirnos en dioses en el aquí y en el ahora, más sublime concepción del hombre que esa no ha existido ni va a existir, lo Judeocristiano corrompe esa visión del hombre. ¿Cómo somos prudentes? como dirían los romanos, haciéndonos éticos, el proceso de hacernos éticos implicaba una toma diaria y mayor de conciencia cada día, tener en cuenta a los demás a la polis, a todo lo existente y a la naturaleza. Una visión sublime necesariamente, pero, el ser humano tiene otro componente instintivo, pasional, esa concepción instintivo pasional los griegos la llamaron el Pathos (una cualidad que despierta emociones (especialmente lástima o pena) es la pura animalidad luchando dialécticamente con la racionalidad impulsa la espiritualización; pero hay algo que debe destacarse, los griegos no se complicaron la vida con que sí seguían el Pathos eran malos hombres pecadores ni nada por el estilo, simple y llanamente tenían más dificultades en su vida personal para hacerse dioses. En la visión Calvinista, yo peco en el plano moral, pero eso no me invalida como sujeto de derechos fundamentales en el plano jurídico, es este otro ropaje de esa antigua concepción griega".

"Bobbio lo dijo mejor que nadie "el ser humano está condenado a ser libre" se recupera así el concepto griego de Ethos y Pathos acabado de analizar en toda su plenitud, por lo tanto en esta perspectiva, la libertad es pura eticidad, Si partimos del concepto liberal de libertad en el sentido griego explicado, necesariamente el mundo de lo jurídico tiene que permitir el goce de esas libertades, pero como ya es un goce concreto, específico, esas libertades de cada uno tienen que jugar, conjugarse con la libertad de los demás y a su vez ya viene limitada ad inicio por el contrato social, ¿cómo podemos valorar, evaluar, medir o determinar el que esas libertades se vuelvan instrumentalizables y manejables por el derecho? El derecho crea su propio lenguaje y al crearlo permite positivizar las libertades y lo que consideramos jurídico desde la perspectiva ideológica liberal, ¿cómo hace el derecho por medio de la regla para hacer esa transformación?, por medio de insertar en cada norma o regla, un "supuesto jurídico", este supuesto jurídico le da el valor de acto jurídico a un acto humano y el valor de hecho jurídico a un hecho humano, así es como las libertades se positivizan, y la ley puede establecer el alcance de las consecuencias de aquellos actos no deseados por el ser humano, los hechos, pero el supuesto jurídico también cumple otras funciones importantes en el mundo interno del derecho" [24]. 
Referecias

[1] J.L. Aranguren, Ética Política, Ediciones Orbis. $2^{\text {a }}$ Edición, 1985

[2] Aristóteles, La Política, Edit. Prometeo.

[3] F.X. Bastida, El Derecho como Creencia, $1^{\mathrm{a}}$. Edición, 2000, Universidad Externado de Colombia, Serie de Teoría Jurídica y Filosofía del Derecho \# 3

[4] El Silencio del Emperador, 1a. Edición en Castellano, Universidad Nacional, 2001

[5] N. Bobbio, La Teoría de las Formas de Gobierno en la Historia del Pensamiento Político, $1^{\text {a }}$ edición, $5^{\text {a }}$ reimpresión, Fondo de cultura económica, México, 1996

[6] Teoría General del Derecho, Edición sin número Editorial Themis, 1992

[7] El Problema del Positivismo Jurídico, $1^{\mathrm{a}}$. Edición, 8 ${ }^{\mathrm{a}}$. Reimpresión, 2004, Editorial Universitaria de Buenos Aires, Biblioteca de Ética, Filosofía del Derecho y Política \# 12.

[8] J. Chevalier, Historia del Pensamiento. Edit. Aguilar, 2a. Edición, 1967 y 1968, Tomos 1, 2, 3,4 .

[9] M.T. Ciceron, Marco Tulio. Sobre las Leyes. Edit. Ariel Universal.

[10] M. Duverger, Instituciones Políticas y Derecho Constitucional, Ed. Ariel, $5^{\text {a Edición, }}$ 1987

[11]Introducción a la Política, Ed. Ariel, 5a. Edición, 1987

[12] D. Grimm, Constitucionalismo y Derechos Fundamentales. Editorial Trotta, Madrid, $1^{\text {a }}$ edición, 2006.
[13] H.L.A. Hart, El Concepto de Derecho, $2^{\mathrm{a}}$. Edición (Reimpresión), Abeledo-Perrot, Buenos Aires

[14] K. Hesse, P. Konrad-Haberle, Estudios sobre la Jurisdicción Constitucional, 1. Edición, Editorial Porrúa, 2005

[15]H. Hofmann, Filosofía del Derecho y del Estado, 1a. Edición, 2002. Universidad Externado de Colombia

[16] H. Kelsen, Teoría Pura del derecho, $1^{\mathrm{a}}$. Edición, Editorial Porrúa, 1991

[17]La idea del Derecho Natural y otros Ensayos, $1^{\text {a }}$. Edición, 2010, ediciones Coyoacán S.A.

[18]_Qué es la Justicia? , 2a . Edición, 1991, Editorial Ariel.

[19] K. Loewenstein, Teoría de la Constitución, $2^{\mathrm{a}}$. Edición, $1^{\mathrm{a}}$. Reimpresión, Ediciones Ariel, 1982

[20] D. Mercado Pérez, Manual de Teoría Constitucional, 1a. Edición, Quito Editores, 2008

[21] J. Pirenne, Historia Universal, las grandes corrientes de la Historia, Editorial Éxito S.A. $5^{a}$ edición, Tomos 1, 2, 3, 4, 5, 6, 7, 8, 9, 10.

[22] L. Recasens Siches, Tratado General de Filosofía del Derecho. Editorial Porrúa, $8^{\text {a }}$ Edición, Editorial Porrúa, 1983

[23] J.J. Rousseau, El Contrato Social. Editorial Sarpe, $1^{a}$. Edición.

[24] R. Vigo, El Iusnaturalismo Actual. -De M.Villey a J. Finnis, $1^{\text {a }}$. Edición, Distribuciones Fontamara, Serie Biblioteca de Ética, Filosofía del Derecho y Política \# 95, 2003 